Ianitskii, O. N. (2006) Ekologicheskaia paradigma kak element kul'tury. Institut sotsiologii Federal'nogo nauchno-issledovatel'skogo tsentra Rossiiskoi akademii nauk [online] Available at: https://www.isras.ru/files/File/Socis/2006-07/yanicki.pdf (access date: 25.03.2020). (In Russ.).

Buechler, S. (1995) New Social Movement Theories. The Sociological Quarterly, vol. 36, no. 3, June, pp. 441-464.

Cortes-Vazquez, J. A. (2019) Against Neoliberal Natures: Environmental Movements, Radical Practice and "the Right to Nature". Geoforum, vol. 98, January, pp. 202-205.

Emilsson, K., Johansson H. and Wennerhag M. (2020) Frame Disputes or Frame Consensus? "Environment" or "Welfare" First Amongst Climate Strike Protesters. Sustainability, 12(3), 882. DOI: https://doi.org/10.3390/su12030882

Melucci, A. (2004) The process of collective identity. In: Social movements and culture / H. Johnston and B. Klandermans (eds). University of Minnesota Press. 296 p. Pp. 41-63.

Rootes, Ch. (2007) Environmental movements. In: The Blackwell Companion to Social Movements / David A. Snow, Sarah A. Soule, and Hanspeter Kriesi (eds.). Blackwell Publishing Ltd. 763 p. Pp. 608-640.

Submission date: 26.03 .2020$.

Галушина Наталья Сергеевна - кандидат культурологии, заведующая кафедрой социокультурных практик и коммуникаций факультета культурологии Российского государственного гуманитарного университета. Адрес: ГСП-3, 125993, Россия, г. Москва, Миусская пл., А. 6. Тел.: +7 (495) 250-68-27. Эл. aspec: galushiny@yandex.ru

Galushina Nataliya Sergeyevna, Candidate of Culturology, Head, Department of Social and Cultural Practices and Communications, Faculty of Cultural Studies, Russian State University for the Humanities. Postal address: 6, Miusskaya Sq., Moscow, Russian Federation, GSP-3, 125993. Tel.: +7 (495) 250-68-27. E-mail: galushiny@yandex.ru

DOI: $10.17805 /$ zpu.2020.2.11

\title{
Искусство и экофилософия: ленд-арт как феномен культуры
}

\author{
А. Р. КОЖАРИНОВА \\ МОСКОВСКИЙ ГУМАНИТАРНЫЙ УНИВЕРСИТЕТ
}

В статье представлен культурфилософский анализ ленд-арта - направления в искусстве, появившегося во второй половине $Х Х$ в.

Анализируются причины появления этого направления в искусстве: отчуждение человека индустриальной цивилизации от природы и глобализация экологических проблем в последней трети XX в. Рассматриваются особенности ленд-арта, к главным из которых можно отнести следующие. Во-первых, путем фиксации на холистическом подходе к системе «человек - природа - культура» в искусстве земли наблюдается снятие закрепленной еще античными философами оппозиции «культура - натура». Во-вторых, в качестве средств художественной выразительности авторами используются принципиально новые для искусства материалы растительного и животного характера (вплоть до микроорганизмов, которые продуктами своей жизнедеятельности могут, к примеру, создавать фон произведения искусства). В-третьих, специфические техники создания произведений ис- 
кусства призваны обеспечивать хрупкость и непрерывную изменчивость арт-объектов, что обусловлено распространением идеи глобального эволюционизма. В-четвертых, новым для искусства становится выход произведений из музейного контекста и его непосредственное соединение с природной средой. В-пятых, интересна и крайне необычна для классического искусства обращенность авторов ленд-арта к телесному опыту зрителей (в частности, к такому необычному для искусства чувству обоняния).

Сделан вывод о том, что ленд-арт становится необычным и интересным инструментом, описывающим и интерпретирующим современную нам новую природную и культурную реальность.

Ключевые слова: ленд-арт; история искусства; искусство ХХ в.; средство художественной выразительности; холизм; арт-объект

\section{BВЕАЕНИЕ}

$\Lambda_{\text {enc }}$ енд-арт - направление в искусстве, зародившееся в США в конце 1960-х гг., манифестировало себя как искусство, протестующее против общества потребления с его навязчивыми рекламными образами, коммерциализацией, конформизмом, банальной и массово растиражированной «пластмассовой» эстетикой. Первым художником ленд-арта стал Алан Сонфист, начавший в 1965 г. создавать арт-объект, представляющий собой небольшой лес, высаженный на Манхэттене. Породы деревьев были выбраны целенаправленно - те, что росли в Америке до прихода туда европейской цивилизации. Авторское название проекта - «Пейзаж времени» - выстраивает связь видоизменяющегося до сегодняшнего дня произведения искусства с доцивилизованными временами. Его включенность в культурный контекст Нью-Йорка и сегодня позволяет жителям мегаполиса хоть в какой-то точке урбанистического пространства испытать медитативное ощущение соединения с природой.

Теоретическая база нового направления была изложена другим известным художником Робертом Смитсоном в его программном манифесте «Выпадение разума в осадок: Земляные проекты». Объектом художественного анализа Р. Смитсона становится земля как таковая, стихию которой индустриальная культура пытается обуздать, проникая в ее хтоническую сущность при помощи копающей, взрывающей, бурящей и всякой другой машинерии (Smithson, 1996: 100). Созидание культурного - строительство - обратная сторона разрушения природного. Результатом подобной двойственной деятельности становятся поглощающие планету «незаконченные города с обломками» (там же: 101). Р. Смитсон эмоционально пишет о растущей энтропии, являющейся мерой необузданной активности цивилизации: бесформенных курганах мусора, горах пыли и грязи, песка и гравия, которые хаотически покрывают и разрушают земную кору. Строгость классических форм в конце XX в. исчезает, и Р. Смитсон предлагает анализировать «бесформенность» постиндустриальной культуры при помощи неклассического дискурса нового искусства.

Попытаемся выделить причины появления ленд-арта, первая из которых, несомненно, кроется в отчуждении человека от природы. Об опасности отчуждения, превращающего человека из действующего субъекта в объект, предупреждали философы И.-Г. Фихте, А. Фейербах, К. Маркс, Э. Фромм и многие другие. Но именно после Второй мировой войны и научно-технической революции середины XX в. проблема отчуждения из абстрактно-философской превратилась в массово осознаваемую (или, во всяком случае, подсознательно переживаемую) - уж слишком всеобщий характер приобрело это явление. Э. Фромм предостерегал: «Человек создал мир рукотворных вещей, какого никогда не существовало прежде. Он разработал сложное общественное устройство, чтобы управлять созданным им техническим механизмом. Однако 
все созданное им возвышается и главенствует над ним. Он чувствует себя не творцом и высшей руководящей инстанцией, а слугой Голема, сделанного его руками» (Фромм, 2006: 87). Отчуждение от природы выделяется среди всех других видов отчуждения своей антигуманистической сущностью, поскольку именно оно покушается на биологическую составляющую природы человека, раскалывает субъекта, лишает ощущения подлинности существования.

Аругой причиной появления ленд-арта стала переориентация современного искусства на осмысление глобальных әкологических проблем современности, связанная с усиливающейся агрессивной экспансией западной техногенной цивилизации в природную среду. Оппозиционная этим процессам протестная активность вылилась в формирование энвайронментализма - идейного течения в политической, экономической, социальной и духовной сферах общественной жизни, непосредственно сосредоточенного на проблеме взаимодействия человека с окружающей средой. В рамках этого нового мышления происходит отказ от доминирующего в культуре Нового времени естественно-научного подхода к природе: снимается софистическая оппозиция культуры - натуры, критикуется идея противопоставления человека как субъекта деятельности и природы как объекта его действий, переосмысляется заданная просветителями идея господства человека над природой, формируются нематериальные ценности, а этические нормы начинают распространяться на взаимодействие общества с природой. Идея восстановления некогда разорванной связи человека с окружающим миром легла в основу ленд-арта.

Хотя ленд-арт признается профессиональным международным әкспертным сообществом как искусство, представляется, что закрепления его места в морфологии этого вида духовной культуры еще не произошло. В самом деле, ленд-арт затруднительно отнести к конкретному виду искусства: это значительно больше, чем ландшафтный дизайн или ландшафтная архитектура, инсталляция или скульптура, акционизм, хеппенинг или перформативная практика. Само название - «искусство земли» - наводит на мысли об опредмеченных в его произведениях идеях синкретизма естественного и искусственного. Соавторство художника и природы выражается не только в очевидном - выборе материалов и техники, переносе арт-объектов из музейного пространства в природное. В ленд-арте границы между пространством художественного произведения и природной средой стираются, и природа становится настоящим соавтором, вступая в субъект-объектные отношения с тонко чувствующим ее художником. Природа наравне с автором определяет выбор средств художественной выразительности, формирует композицию, определяет ритм, пропорции, тектонику произведения искусства.

Иенд-арт - молодое искусство, которое, конечно, не может конкурировать с временными масштабами существования классического искусства. Однако за столь незначительный период это направление уже приобрело ряд специфических особенностей, рассмотрение которых представляется важным для анализа искусства земли как культурного феномена.

\section{СНЯТИЕ АИХОТОМИИ «КУАБТУРА - НАТУРА»}

Основой для произведений ленд-арта является сама поверхность Земли. Разъединение между ней и собственно произведением искусства без нарушения целостности артефакта в большинстве случаев не представляется возможным. Сама планета включается в художественный процесс и становится со-творцом художника, что акценти- 
рует идею полной гармонии искусства и природы, их взаимного растворения, перетекания друг в друга. Так, одна из главных работ Р. Смитсона «Спиральная дамба» (1970 г., штат Юта, США), ставшая «иконой» ленд-арта, с момента создания периодически меняла свою конфигурацию, то уходя под воду, то поднимаясь над ней в зависимости от количества осадков в регионе. Ее окраска тоже варьировалась в связи с нарастанием слоя соли на поверхности черного базальта, из которого сделан материал дамбы. Более того, служащая фоном озерная вода, окружающая дамбу, за все время существования художественного объекта под воздействием живущих в озере микроорганизмов меняла свой цвет от кроваво-красного до бледно-розового, что прогнозировалось автором в процессе выбора места ее создания 1 . Таким образом, не только природные силы, но и минералы и микробы обусловили диалектику арт-объекта. Важен тот факт, что процесс постоянного изменения энтропии культурно-природной системы был не только дозволен и предусмотрен автором, представляется, что именно он стал сущностью проекта.

Зачастую авторы искусства земли сознательно создают иллюзию «нерукотворности» своего произведения. Например, представители российской группы «Обледенение архитекторов» выстроили в 2002 г. в лесу на берегу Клязьминского водохранилища сооружение, представляющее собой строительные леса, по которым можно перемещаться, спускаясь и поднимаясь на их разные уровни, вплоть до вершин деревьев. Эти сооружения сделаны из негниющих пород итальянских деревьев, что символизирует диалектическую связь настоящего и будущего, устремляет художественный образ в вечность. Но контекстом искусственной конструкции является живой лес, что, собственно, и дало название проекту: « Аеса в лесах». Авторами задумано, что проект будет развиваться, лесные деревья прорастут сквозь искусственные доски, создавая пространство органической целостности природного и культурного: « $\Lambda$ ет через сто пятьдесят... уже нельзя будет понять, где - лес, а где - леса $»^{2}$.

\section{ХОАИСТИЧЕСКИЙ ПОАХОА}

Холистический подход к системе «человек - природа - культура» основан на идеях В. И. Вернадского, П. Тейяра де Шардена, Н. Ф. Федорова, А. А. Чижевского, А. Швейцера, А. Аеопольда. Системный подход требует междисциплинарности, которая была реализована, в частности, в появлении новой области знаний - экологической әстетики, целью которой является формирование взгляда на Землю как на эстетический объект. Экологическая эстетика основана на следующих принципах: наибольшей эстетической ценностью является дикая природа; ее следует ценить и уважать такой, какая она есть, нельзя навязывать природе свои вкусы; любование природными объектами бескорыстно, они ценны сами по себе, а не в связи с тем удовольствием, которое они доставляют людям; не существует некрасивой и нецелесообразной природы; природные места, имеющие эстетическую ценность, должны быть взяты под охрану (Борейко, 2005: 38).

Иенд-арт активно использует следующие принципы природоохранной эстетики. Во-первых, арт-объекты чаще всего располагаются в не затронутых хозяйственной деятельностью ареалах, где дикая природа саморегулируется естественным образом за счет внутренних процессов. Во-вторых, художники зачастую выбирают труднодоступные места, и предполагается, что идея «пути» к арт-объекту должна стать составляющей акта его восприятия. В-третьих, у рассматриваемого направления в искусстве отсутствует коммерческая направленность, произведения искусства в равной сте- 
пени принадлежат всем, кто захочет доставить себе удовольствие от их созерцания. Наконец, эстетическая категория прекрасного годится для описания любого природного объекта.

Таким образом, теории и практики ленд-арта, построенные на фундаментальности системы «человек - природа - искусство», непосредственным образом вписываются в парадигму «философии целостности».

\section{СПЕЦИФИЧЕСКИЕ МАТЕРИААЫ И ТЕХНИКИ}

Аенд-арт раскрывает потенциал природных материалов, используя в качестве средств художественной выразительности воду, грязь, землю и песок, лед и снег, ветки и листья деревьев, травы и плоды, ростки зерновых культур, отходы жизнедеятельности микроорганизмов и пр. Тишина или, напротив, звуки природы (шорох дождя, журчание ручья, шум водопада) дополняют впечатление. Солнечные лучи, пар, туман, радуга, электрические разряды на какое-то время тоже могут стать частью художественного произведения, что придает еще большую выразительность и многослойность авторскому тексту.

Художественные техники и практики ленд-арта тоже весьма оригинальны, достаточно вспомнить хрестоматийные: высаживание деревьев Йозефом Бойсом (1982), протаптывание тропинок Ричардом Аонгом (1967) (инструментом художника становятся его ноги, холстом - почва). С точки зрения художественной техники можно отдельно выделить проекты самого известного российского представителя ленд-арта Николая Полисского. Так, с 2004 г. по настоящее время в деревне Никола-Иенивец Калужской области автор устраивает на Масленицу перформативное уничтожение арт-объектов, ежегодно сжигая по одной своих инсталляций. А с 2000 по 2012 г. в Никола- Аенивце, Москве и Перми Н. Полисский провел несколько акций, во время которых горожане и сельские жители массово лепили снеговиков. Причем технологии лепки из снега менялись в зависимости от места создания арт-объектов - от лепки с одновременным одеванием снеговиков в соответствии с культурными традициями жителями Никола-Аенивца до микеланджеловского отсекания всего лишнего во время акции «Парад снеговиков» в Перми.

\section{ХРУПКОСТЬ}

Произведение ленд-арта, в отличие от классического искусства, не предназначено Аля вечного существования. В нем изначально присутствует идея вероятного разрушения стихией, животными, людьми, естественным ходом годовых и суточных циклов, экологическими и климатическими изменениями в любой момент его существования. Создатель не знает, какое время отпущено его творению, однако уязвимость и возможность бесповоротного распада не смущает автора.

Хрупкость произведений ленд-арта лучше всего иллюстрируют работы Ажима Аонована, ставшего знаменитым благодаря рисункам на песчаных пляжах, создаваемым при помощи палок и граблей. Эти арт-объекты существуют от отлива до прилива, а выставочными образцами становятся их фотографии или видеосъемки, сделанные при помощи дронов. В 2010 г. Аонован вместе с помощниками нанес масштабные рисунки общей площадью девять квадратных километров на поверхность льда озера Байкал (здесь инструментами живописца стали веники).

Художник песка (так А. Аонован сам себя называет) подчеркивает, что на создание произведения затрачивается много физических сил, но, заканчивая процесс создания 
изображений и попадая в центр нарисованных им спиралей и концентрических кругов (а чаще всего именно эти фигуры художник наносит на поверхность земли), автор испытывает медитативное ощущение, о чем написал 26 марта 2016 г. на своей персональной странице в Facebook: «Я могу сказать, что, когда я иду в центр спирали и стою там после стольких часов физических усилий и умственной концентрации, я испытываю чувство покоя, которое ничуть не уменьшается по мере того, как начинаются приливы и волны и рисунок медленно смывается».

Освобождение автора от желания обладать законсервированно существующим произведением искусства становится здесь иллюстрацией разрушения концепций человека как хозяина природы и автора как хозяина своего творения.

\section{ТЕМПОРААЬНОСТЬ}

Ранее уже было подчеркнуто непрерывное формоизменение произведений лендарта, основанное на эволюции всех включенных в них элементов. Аиалектика формы может иметь как антропогенный источник (например, как у создающего и разрушающего свои инсталляции Н. Полисского), так и природный характер ( «Спиральная дамба» Р. Смитсона). Идея глобального эволюционизма, являющаяся фундаментальной Аля постнеклассической науки, лежит также и в основе рассматриваемого нами искусства. Современная культура выстраивает особенные модели отношений человека со временем. Самой распространенной является концепция нахождения в моменте ( «здесь-и-сейчас»). Конечно, подобный взгляд на время делает невозможной онтологизацию этой философской категории в массовом сознании, десакрализирует сформированное в традиционных религиозных культурах восприятие времени, исключает масштабное космическое восприятие фундаментального измерения нашего бытия.

Вероятно, самым впечатляющим ленд-арт проектом, работающим с проблемой онтологического осмысления категории «время», является работа Ажеймс Таррелла «Кратер Родена», представляющая собой строящийся с 1972 г. по настоящее время арт-объект, помещенный непосредственно в жерле потухшего вулкана в Северной Аризоне.

Автор превращает кратер в обсерваторию, предназначенную для наблюдения за космическими явлениями. В хтоническом пространстве, к взаимодействию с которым тяготели многие художники всех времен и народов, Аж. Таррелл разместил сеть подземных коридоров, сориентировав их в соответствии с системой природного освещения. В этом грандиозном сооружении имеет значение не только факт естественного происхождения света (только излучаемый или отражаемый свет небесных тел попадает внутрь расположенных в жерле коридоров). Не менее важен факт тщательного выстраивания геометрии внутреннего пространства арт-объекта с детально просчитанными будущими траекториями перемещения небесных тел в грядущем тысячелетии.

По задумке автора, поднявшийся на «Кратер Родена» посетитель попадет в уникальную ситуацию единения со Вселенной, чему способствуют и окружающая зрителя тишина пустыни, и особая топография проекта, заключенная в непосредственной близости как к подземным геологическим слоям под ним, так и звездному небу над ним. Наблюдатель становится чем-то большим, чем просто зритель классического произведения искусства: он биологически ощущает ход времени, подчиняющего себе диалектику микро- и макрокосма в натурфилософском понимании этих терминов.

Возможен и противоположный подход к работе со временем. Так, Н. Полисский сознательно выбирает кратковременно существующие материалы: тающий снег, 
гниющее сено, сгорающие в печах дрова, полагая, что память о существовавших и исчезнувших под действием времени арт-объектах - самое надежное хранилище его работ ${ }^{3}$.

\section{АЕНА-АРТ И МУЗЕЙНОЕ ПРОСТРАНСТВО: «УХОА-И-ВОЗВРАТ »}

Привычная музейная репрезентация художественного произведения по понятным причинам невозможна для этого направления искусства. Возможно, институализация искусства земли состоится в будущем, но пока художественным пространством бытования ленд-арта становятся холмы, пустыни, леса, озера и моря - любое природное пространство, выбранное художником. Некоторые творения могут быть видимы только с высоты птичьего полета или даже с космического спутника ${ }^{4}$ Оппозиционность музейному пространству объясняется здравым смыслом: работы слишком масштабны и не могут быть оторваны от контекста, составляющего их сущность. Однако интересно, что в случае «земельного искусства» совершается движение как бы в противофазе, навстречу традиционному перемещению оригинала из мастерской художника в музей. В данном случае оригинал остается на месте его создания, а в художественные институции попадают фото- или видеокопии. «Техническая воспроизводимость» (В. Беньямин) хоть и приводит к утрате ауры оригинала, но доступная большинству зрителей экспозиционная ценность произведения искусства в данном случае может существовать и у копии.

\section{РЕАНИМАЦИЯ БИОАОГИЧЕСКОГО: ОБРАЩЕНИЕ К ТЕАЕСНОМУ ОПЫТУ ЗРИТЕАЯ}

Как любое искусство, ленд-арт пытается пробудить не столько сознание, сколько эмоции зрителей. При этом «художники земли» могут апеллировать к тем органам чувств, с которыми никогда не работало классическое искусство.

Иллюстрацией специфического восприятия художественного произведения может стать проект Уолтера Ае Марии «Нью-йоркская земляная комната» (1977). В выставочный зал автор перенес 200 кубометров черной земли общим весом 127 тонн, которую равномерно разложил в пустой комнате с абсолютно белыми стенами. Согласно задумке автора, зритель в абсолютной тишине с закрытыми глазами должен был просто вдыхать запах сырой земли, т. е. возможность подключения к восприятию инсталляции зрения и слуха сознательно сведены к минимуму. В лаконично организованном пространстве земляной комнаты главным средством художественной выразительности становится запах влажной почвы, а контраст между ним и воздухом мегаполиса дополняет впечатление, возвращая посетителя к детскому абстрактному восприятию мира.

\section{ПЕРФОРМАНСИЗМ}

Одним из первых примеров масштабной экоакционистской деятельности стал проект Йозефа Бойса «7000 дубов», стартовавший в 1982 г. и закончившийся уже после смерти автора в 1987 г. По мысли воевавшего в «Цюфтваффе» в годы Второй мировой войны художника, высаживание деревьев по направлению от немецкого города Кассель к границам СССР могло помочь в залечивании травм прошлого путем прямой демократии (для Й. Бойса было принципиально, что он начал высаживать деревья лично, а затем, следуя его примеру, к нему стали присоединяться жители близлежащих городов). 
Отметим, что вовлечение зрителя в творческо-экологический процесс было изначально задумано художником. Он совершал плановые поездки по городам, расположенным на линии проекта, убеждая жителей принять в нем участие, встав на место художника. Так проект приобрел смысловую многоуровневость: экологическое и эстетическое трансформировалось в этическое, антивоенное, коммуникационное и интегративное.

Аругой иллюстрацией художественной деятельности, претендующей на роль социального высказывания, стала работа Агнес Аенес, которая в 1982 г. вместе с помощниками вручную расчистила самую большую мусорную свалку Манхэттена и привезла туда плодородную почву. На самой дорогой земле в мире она высадила пшеницу, которую поливала, обрабатывала от грибка и вредителей в течение всего лета. Результатом существования проекта «Пшеничное поле - конфронтация» стал урожай здоровой пшеницы. Сутью проекта А. Аенес было обращение к проблемам противостояния природы и цивилизации, смене ценностных приоритетов.

\section{ЗАКАЮЧЕНИЕ}

Итак, появление ленд-арта во второй половине XX в. обусловлено обострением глобальных экологических проблем и фактическим отрывом человека от собственного природного начала. Аенд-арт обладает следующими характеристиками: стремление к восстановлению целостности системы «человека - природа - культура», чем объясняется как выбор специфических для искусства средств художественной выразительности, так и факт перемещения арт-объектов из музейного в природное пространство; подчеркнутая хрупкость и непрерывная изменчивость арт-объектов, иллюстрирующая идею глобальной эволюции; обращенность к тем органам чувств, к которым никогда не апеллировало классическое искусство.

Сила идей, содержащаяся в произведениях ленд-арта, доминирует над их нетрадиционной формой, что делает это искусство инструментом описания новой реальности и ее интерпретации. Использование своеобразных художественных материалов и техник, перемещение арт-объектов в нетрадиционные для классического искусства контексты освежает и обостряет восприятие художественных произведений, и это увеличивает возможности ленд-арта в переформатировании ценностных систем и трансформации внутреннего мира зрителя, помогая ему осознать грядущие цивилизационные риски.

\section{ПРИМЕЧАНИЯ}

1 Вронская К. (2017) Роберт Смитсон и философия Мартина Хайдеггера [Электронный ресурс]// Сигма : платформа для публикации текстов о человеке, культурных явлениях и обществе. URL : https://syg.ma/@tina_vrosnkaya/robiert-smitson-i-filosofiia-martina-khaidieghghiera (дата обращения: 02.04.2020).

2 Кокодзте Е. (2003) Архитектура для реальной жизни [Электронный ресурс]// Искусство. № 2 (526). URL : https://iskusstvo-info.ru/arhitektura-dlya-realnoi-zhizni/ (дата обращения: 01.03.2020).

3 Боде М. (2001) Интервью с Николаем Полисским «Место моих произведений — в памяти» [Электронный ресурс] // Русский журнал. URL : http://old.russ.ru/culture/vystavka/20011002_ bode.html (дата обращения: 02.03.2020).

4 Примеров работ геологических масштабов множество: парк «Рельефная скульптура» с изображениями представителей животного мира, обитающих в долине реки Иллинойс Майкла Хайзера; находящиеся на стыке тысячелетней сельскохозяйственной традиции культивиро- 
вания национального продукта и живописного искусства, созданные руками селекционеровхудожников рисовые поля в Инакадате (Япония); видимые из космоса монументальные геоглифы Эндрю Роджерса, последовательно воздвигаемые им в пустынях, фьордах, ущельях и национальных парках всех семи континентов и визуализирующие важнейшие для местных культур символы; земельные портреты, натюрморты и пейзажи американца Стэна Херда, в которых содержатся как рекламные изображения, так и цитаты из классических полотен; «Сад космических размышлений» Чарльза и Мэггги Аженксов, моделирующий нашу Вселенную в миниатюре; «Поле молний» Уолтера Ае Мария, представляющее собой лес громоотводов, притягивающих молнии во время грозы, в пустыне Нью-Мексико и многие другие.

\section{СПИСОК АИТЕРАТУРЫ}

Борейко, В. Е. (2005) Природоохранная эстетика в вузе. Киев : Киевский эколого-культурный центр. 80 с.

Фромм, Э. (2006) 3доровое общество. М. : АСТ. 539 с.

Smithson, R. (1996) A Sedimentation of the Mind: Earth Projects // Smithson, R. The Collected Writings. California : University of California Press, Berkeley and Los Angeles. 389 p. Pp. 100-113.

Аата поступления: 29.05.2020 г.

\section{ART AND ECOPHILOSOPHY: LAND ART AS A CULTURAL PHENOMENON}

\section{A. R. KOZHARINOVA}

\section{MOSCOW UNIVERSITY FOR THE HUMANITIES}

The article presents a cultural-philosophical analysis of land art - a direction in art that appeared in the second half of the $20^{\text {th }}$ century.

The author analyzes the reasons for the emergence of this trend in art: the alienation of the industrial civilization man from nature and the globalization of environmental problems in the last third of the $20^{\text {th }}$ century. The features of land art are analyzed, the main of which are the following. Firstly, by fixing on a holistic approach to the "human-nature-culture" system in the art of the earth, the removal of the "culture-nature" opposition fixed by ancient philosophers is observed. Secondly, as a means of artistic expression, the authors use fundamentally new for art materials of plant and animal nature (up to microorganisms, whose products of life can, for example, create the background of a work of art). Thirdly, specific techniques for creating works of art are designed to ensure the fragility and continuous variability of art objects, due to the spread of the idea of global evolutionism. Fourthly, the emergence of works from the museum context and its direct connection with the natural environment becomes new for art. Fifthly, the appeal of land art authors to the bodily experience of the audience (in particular, to smell - such an unusual sense for art) is interesting and extremely unusual for classical art.

The author concludes that land art is becoming an unusual and interesting tool that describes and interprets our contemporary natural and cultural reality.

Keywords: land art; history of art; $20^{\text {th }}$-century art; means of artistic expression; holism; art object

\section{REFERENCES}

Bode, M. (2001) Interv'ju s Nikolaem Polisskim «Mesto moih proizvedenij — v pamjati». Russkij zhurnal. [online] Available at: http://old.russ.ru/culture/vystavka/20011002_bode.html (accessed: 02.03.2020)

Borejko, V. E. (2005) Prirodoobrannaja jestetika v vuze. Kiev, Kiev Ecological and Cultural Center. 80 p. (In Russ.).

Vronskaja, K. (2017) Robert Smitson i filosofija Martina Hajdeggera. Sigma: platforma dlja publikacii tekstov o cheloveke, kul'turnyb javlenijab $i$ obshbestve. [online] Available at: https://syg. ma/@tina_vrosnkaya/robiert-smitson-i-filosofiia-martina-khaidieghghiera (accessed 02.04.2020) (In Russ.). 
Kokodzte, E. (2003) Arhitektura dlja real'noj zhizni. Iskusstvo, no 2 (526), [online] Available at: https://iskusstvo-info.ru/arhitektura-dlya-realnoi-zhizni/ (accessed: 01.03.2020) (In Russ.).

Fromm, Je. (2006) Zdorovoe obshbestvo. Moscow, AST. 539 p. (In Russ.).

Smithson, R. (1996) A Sedimentation of the Mind: Earth Projects. Smithson, R. The Collected Writings. California, University of California Press, Berkeley and Los Angeles. 389 p. Pp. 100-113.

Submission date: 29.05 .2020$.

Кожаринова Анна Ростиславовна - кандидат философских наук, доцент кафедры философии, культурологии и политологии Московского гуманитарного университета. SPIN-код РИНЦ: 8434-2370. Адрес: 111395, Россия, г. Москва, ул. Юности, д. 5. Тел.: +7 (499) 374-55-11. Эл. aApec: anna_adv@inbox.ru.

Kozharinova Anna Rostislavovna, Candidate of Philosophy, Associate Professor, Department of Philosophy, Cultural Studies and Political Science, Moscow University for the Humanities. RISC SPIN code: 8434-2370. Postal address: 5, Yunosti St., Moscow, Russian Federation, 111395. Tel.: +7 (499) 374-55-11. E-mail: anna_adv@inbox.ru

DOI: $10.17805 /$ zpu.2020.2.12

\title{
Ценностные ориентации поколений сотрудников и организационная культура библиотеки
}

\author{
Е. В. ГРАКОВА, М. В. МАСЛАКОВА \\ ТЮМЕНСКИЙ ГОСУДАРСТВЕННЫЙ ИНСТИТУТ КУЛЬТУРЫ, \\ Т. Г. ДОЛГАНОВА \\ ТЮМЕНСКИЙ ГОСУДАРСТВЕННЫЙ ИНСТИТУТ КУЛЬТУРЫ; \\ ФИЗИКО-МАТЕМАТИЧЕСКАЯ ШКОЛА, Г. ТЮМЕНЬ
}

В статье рассматриваются вопросы применения к анализу организационной культуры библиотеки теории поколений. Организационная культура библиотеки определяется как совокупность мировоззренческих представлений ценностных ориентаций, моделей поведения и взаимоотношений в коллективе, независимо от занимаемого места в библиотеке, разделяемых всеми ее членами.

В качестве ядра организационной культуры библиотеки рассматриваются ценности (личностные и профессиональные), оказывающие влияние на информационно-культурный капитал библиотеки. Для характеристики ценностных ориентаций рассмотрены некоторые положения теории поколений. Отмечается, что в современных библиотеках персонал состоит из представителей трех поколений: беби-бумеров, поколения $X$ и поколения $Y$. Указаны профессиональные ценности работников библиотек, их значимость в организационной культуре.

Изучение теории поколений имеет значение для построения и развития организационной культуры библиотек, обладающих разнородным составом сотрудников. Совершенствование организационной культуры библиотеки с точки зрения модернизации информационного профессионализма сотрудников и учета их ценностных ориентаций целесообразно в контексте теории поколений.

Ключевые слова: информационная культура, организационная культура библиотеки; ценностные ориентации; персонал библиотеки; поколения; поколение беби-бумеров; поколение $X$; поколение $Y$ 